\title{
Inferior retractor plication surgery for lower lid entropion with trichiasis in ocular cicatricial pemphigoid
}

\author{
Mark J Elder, John K G Dart, Richard Collin
}

\begin{abstract}
Aims-To assess the outcome of inferior retractor plication surgery for lower lid entropion in patients with ocular cicatricial pemphigoid (OCP). This technique avoids surgery on the conjunctiva that can result in exacerbations of disease activity. Methods-This prospective study assessed the outcomes of a standard 'Jones' type plication in 14 lids of 10 patients with OCP. Seven patients were taking systemic immunosuppression and no patients had conjunctival inflammation for the 4 months before surgery.

Results-Life table analysis showed a 77\% chance of anatomical success at 2 years and a $54 \%$ chance of completely preventing lash-globe touch. The surgery did not cause clinical activation of conjunctival inflammation or other complications. Anatomical failure was primary $(n=2)$ and due to late cicatrisation $(n=1)$. Three further cases had restoration of normal anatomy but the patients had persistently misdirected lashes that touched the globe. Conclusion-This technique gives good anatomical success over long periods and is particularly safe when there is no conjunctival inflammation present before surgery.
\end{abstract}

(Br f Ophthalmol 1995; 79: 1003-1006)

Trichiasis is a common and potentially sight threatening complication of ocular cicatricial pemphigoid (OCP) and is the major risk factor for microbial keratitis. ${ }^{12}$ It may also cause punctate epitheliopathy, corneal abrasions, conjunctival metaplasia, provoke additional conjunctival inflammation, and increase ocular surface symptoms.

Eyelashes may touch the globe either because of entropion, aberrantly directed lashes (misdirected lashes) arising from the anterior lid margin, or because of metaplastic lashes arising from the posterior lid margin. In OCP, this is usually the result of cicatricial entropion secondary to posterior lamellar shortening from conjunctival stromal fibrosis. However, the lower lid may have additional mechanisms contributing to the entropion unrelated to the cicatrisation, such as overriding of the orbicularis and laxity of the lower lid retractors. Both are common causes of entropion in the elderly. ${ }^{3}$

For moderate cicatricial entropion, the common surgical procedures include mucous membrane grafting, ${ }^{45}$ full thickness lid resection, and a modified Wies procedure. ${ }^{6}$ Both of these involve directly operating on the conjunctiva. Unfortunately in OCP this often triggers conjunctival inflammation and further cicatrisation which can lead to surgical failure ${ }^{478}$ Therefore, there is virtue in any entropion procedure that does not involve operating on the conjunctiva. ${ }^{9}$

The lower lid retractors function to adjust the vertical height of the lid with up and downgaze. The cornea can rotate downwards about $55^{\circ}(10 \mathrm{~mm})$ and this is accompanied by lower lid descent of about $5 \mathrm{~mm}$. A lack of lower lid movement on vertical downgaze suggests a defective retractor mechanism. Anatomically, the retractors are slips of fascia that extend mainly from the inferior rectus muscle to the inferior tarsal plate. A smaller contribution is made from the inferior palpebral muscle and inferior oblique fascia. ${ }^{10}$ If the inferior retractor fascia is surgically shortened then the enhanced tension on the tarsus helps to resist entropion. Performing the surgery through the skin approximately overlying the inferior border of the tarsal plate prevents orbicularis overriding by providing a fibrous barrier. Suturing of the plicated retractors to the anteroinferior aspect of the tarsal plate and to the orbicularis muscle and skin also ensures that the retractor tension is transferred to the anterior lamella. This assists eversion of the lid and these factors are the basis of the 'Jones procedure' of inferior retractor plication for lower lid entropion. 310

The aim of this study was to assess the outcome of the Jones procedure in OCP in patients whose disease was medically well controlled before surgery.

\section{Materials and methods}

Patients were selected for the study from the corneal and external disease clinics at Moorfields Eye Hospital over 24 months from September 1992. All patients with OCP who had lower lid cicatricial entropion with trichiasis affecting more than one third of the lid width were recruited. The patients were referred to the lid clinic of Moorfields Eye Hospital and the surgery was performed under their care (JROC). The actual surgery was deferred until the affected eye had been free from inflammation for a minimum of 4 months or until the inflammation was at a minimum.

Ocular cicatricial pemphigoid was diagnosed by conjunctival biopsy and characteristic 
Table 1 Patient details and outcomes of inferior retractor plication surgery for lower lid entropion

\begin{tabular}{|c|c|c|c|c|c|c|c|}
\hline $\begin{array}{l}\text { Patient } \\
\text { number }\end{array}$ & Side & $\begin{array}{l}\text { Formix depth } \\
\text { (preop, mm) }\end{array}$ & Complications & $\begin{array}{l}\text { Formix depth } \\
\text { (final, mm) }\end{array}$ & $\begin{array}{l}\text { Follow up } \\
\text { (months) }\end{array}$ & $\begin{array}{l}\text { Oral } \\
\text { immunosuppression }\end{array}$ & $\begin{array}{l}\text { Topical } \\
\text { steroids }\end{array}$ \\
\hline \multicolumn{8}{|c|}{ Successful cases } \\
\hline 1 & L & 5 & - & 5 & 21 & $\mathbf{Y}$ & - \\
\hline 1 & $\mathbf{R}$ & 4 & - & 4 & 17 & $\bar{Y}$ & - \\
\hline 2 & $\mathrm{~L}$ & 1 & - & 1 & 14 & - & $\mathbf{Y}$ \\
\hline 3 & $\overrightarrow{\mathbf{R}}$ & 3 & - & 3 & 9 & $\mathbf{Y}$ & - \\
\hline 4 & $\vec{L}$ & 3 & - & 3 & 8 & $\mathrm{Y}$ & - \\
\hline 4 & $\overline{\mathbf{R}}$ & 3 & - & 3 & 9 & $\mathrm{Y}$ & - \\
\hline 5 & $\mathbf{R}$ & 7 & Yes` & 7 & 9 & $\bar{Y}$ & - \\
\hline 6 & $\mathbf{R}$ & 3 & - & 3 & 24 & - & - \\
\hline 7 & $\vec{L}$ & 5 & - & 5 & 24 & - & $\mathbf{Y}$ \\
\hline 7 & $\mathbf{R}$ & 5 & _- & 5 & 20 & - & $\mathrm{Y}$ \\
\hline 8 & $\mathbf{L}$ & 3 & - & 3 & 17 & $\mathbf{Y}$ & - \\
\hline \multicolumn{5}{|c|}{ Unsuccessful cases } & \multicolumn{3}{|l|}{$\begin{array}{l}\text { Time to fail } \\
\text { (months) }\end{array}$} \\
\hline 8 & $\mathbf{R}$ & 4 & - & 2 & $8 t$ & $\mathbf{Y}$ & - \\
\hline 9 & $\mathbf{R}$ & 1 & - & $\overline{1}$ & 1 & $\mathbf{Y}$ & - \\
\hline 10 & $\overrightarrow{\mathbf{R}}$ & 4 & - & 4 & 3 & $\mathbf{Y}$ & - \\
\hline
\end{tabular}

*The conjunctiva became inflamed after 10 days. At 1 month a suture abscess developed. + Severe ocular inflammation and cicatrisation developed 6 months postoperatively. Cases $6,7 \mathrm{~L}$, and $7 \mathrm{R}$ were anatomically successful but failed at 6,3 , and 8 months respectively as a result of aberrant lashes $(n=2)$ and metaplastic lashes $(n=1)$ touching the globe.

clinical appearances. A bulbar conjunctival biopsy was performed before surgery on all but one patient and was defined as positive if there was basement membrane deposition of IgG, IgA, or complement. Patients who were biopsy negative had characteristic subepithelial fibrosis and progressive conjunctival cicatrisation. Preoperatively, the trichiatic lashes were assessed as arising from the anterior or posterior lid margin. No patient had previous lid surgery.

All surgery was performed under local anaesthesia. A standard lower lid retractor plication was performed as described by Jones et al. ${ }^{3}{ }^{10} \mathrm{~A}$ full width, horizontal skin incision was made 4-6 $\mathrm{mm}$ inferior to the lid margin. The orbicularis was split parallel to the skin incision, the inferior border of the tarsal plate was exposed, and the orbital septum was divided. The slips of the lower lid retractors were exposed and confirmed by voluntary up and downgaze. Multiple, interrupted $6 / 9$ polyglycolic acid sutures were placed through the retractors, the inferior tarsal plate, the orbicularis muscle and brought out through the skin. The amount of retractor tendon shortening (typically 6-10 $\mathrm{mm}$ ) was individualised such that there was slight lid eversion at the end of surgery. The conjunctiva was not breached during the surgery. Postoperatively, no new topical or systemic treatment was administered.

A proforma was used to record the data prospectively using the same observer (MJE). Follow up was at 1 month, 3 months, and approximately 3 monthly thereafter. Two definitions of success were used; anatomical success where the lid margin was restored to its normal position and complete success where

Table 2 Cumulative chance of anatomical success of inferior retractor plication surgery for lower lid entropion

\begin{tabular}{lllllll}
\hline $\begin{array}{l}\text { Post } \\
\text { treatment } \\
\text { interval } \\
\text { (months) }\end{array}$ & $\begin{array}{l}\text { Number of } \\
\text { lids at } \\
\text { interval } \\
\text { beginning }\end{array}$ & $\begin{array}{l}\text { Number of lids } \\
\text { withdrawn } \\
\text { in the } \\
\text { interval }\end{array}$ & $\begin{array}{l}\text { Number } \\
\text { of lids } \\
\text { at risk }\end{array}$ & $\begin{array}{l}\text { Number of } \\
\text { failures } \\
\text { during the } \\
\text { interval }\end{array}$ & $\begin{array}{l}\text { Chance } \\
\text { of } \\
\text { success }\end{array}$ & $\begin{array}{l}\text { Cumulative } \\
\text { chance of } \\
\text { success }\end{array}$ \\
\hline $0-3$ & 14 & 0 & 14 & 2 & 0.8571 & $0 \cdot 8571$ \\
$4-6$ & 12 & 0 & 12 & 0 & 1.0 & 0.8571 \\
$7-9$ & 12 & 4 & 10 & 1 & 0.9000 & 0.7714 \\
$10-12$ & 7 & 0 & 7 & 0 & 1.0 & 0.7714 \\
$13-15$ & 7 & 1 & $6 \cdot 5$ & 0 & 1.0 & 0.7714 \\
$16-18$ & 6 & 2 & 5 & 0 & 1.0 & 0.7714 \\
$19-21$ & 4 & 2 & 3 & 0 & 1.0 & 0.7714 \\
$22-24$ & 2 & 2 & 1 & 0 & 1.0 & 0.7714 \\
\hline
\end{tabular}

there were no eyelashes touching the globe. Adequate lid closure was assessed on each visit. The lower lid fornix depth was measured optically as the vertical distance between the 6 o'clock limbus and the lower fornix. The normal depth is approximately $11 \mathrm{~mm} .{ }^{11}$ This measurement was repeated at each clinic visit.

\section{Results}

Fourteen lids of 10 patients were enrolled (Table 1). The mean age was 74.8 (SD 6.9) years and ranged from 67 to 87 years. Five patients were men and eight had a positive biopsy. Seven patients were taking oral immunosuppressive drugs (cyclophosphamide, dapsone, or sulphapyridine) and an additional two patients were taking topical steroids at the time of surgery. All patients had no inflammation for a minimum of 4 months before surgery except for one where the inflammation was mild and unable to be minimised further (No 3, Table 1). All patients had preoperative trichiatic lashes arising from the anterior lid margin, two had additional lashes arising from the posterior margin, and one had additional metaplastic lashes.

The details of the fornix depth and surgical outcomes are given in Table 1 . There were no perioperative complications. Postoperatively, one eye developed conjunctival inflammation after 10 days (No 5). This was controlled with topical steroids. The same lid developed a suture abscess at 1 month which resolved with topical antibiotics and removal of the suture. There were no other complications or cases of inadequate lid closure.

The results of the success of the surgery were analysed using an actuarial method (Table 2) and are presented as a life table ${ }^{12}$ (Fig 1). Overall, there was good anatomical success of $77 \%$ at 2 years and complete success of $54 \%$ at 2 years. There was a trend towards a lower anatomical success with a shallower lower fornix but this was not statistically significant; mean depth (SD) and 95\% confidence intervals for successful cases, $3.8 \mathrm{~mm}$ (1.6), 2.9-4.7 $\mathrm{mm}$, unsuccessful cases $2 \cdot 3$ $(1.5) \mathrm{mm}, 0.6-4.0 \mathrm{~mm}$. Of the three anatomical failures, one was due to an episode of severe 


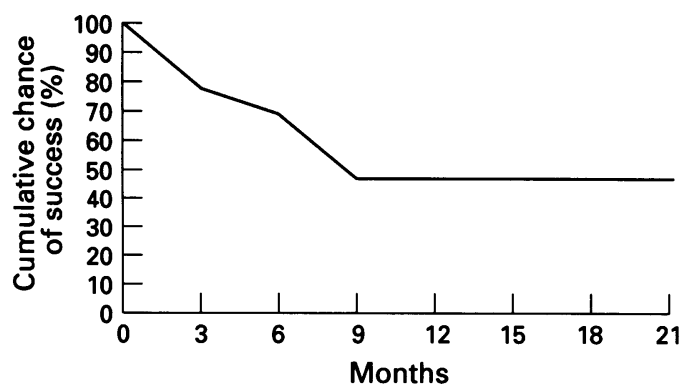

Figure 1 Cumulative chance of success of inferior retractor plication surgery for lower lid entropion.

ocular inflammation and cicatrisation which developed 6 months postoperatively and required oral cyclophosphamide and prednisolone to abate (No 6). Therefore; this lid failed because of ongoing disease rather than direct surgical failure. Otherwise, no failure was due to further OCP associated cicatrisation. The other two failures were primary and an adequate lid position was never achieved postoperatively although there was temporary symptomatic relief as a result of lid swelling that held the lashes away from the globe. A further three cases $(6,7 \mathrm{~L}$, and $7 \mathrm{R})$ were anatomically successful but failed at 6,3 , and 8 months respectively owing to aberrant, misdirected lashes $(n=2)$ and metaplastic lashes $(n=1)$ touching the globe. No anatomically successful cases had postoperative trichiasis from anterior lid margin lashes present preoperatively.

\section{Discussion}

The inferior retractor plication procedure has been moderately successful at everting the lid and moving the lashes away from the globe. It is encouraging that only one eye had surgically induced inflammation and that this was mild enough to be controlled with topical steroids alone. Further, there was no cicatrisation induced by the surgery and the only surgical complication was one suture abscess. These data support the notion that conjunctival inflammation must be resolved before surgery and that the procedure itself should avoid the conjunctiva. ${ }^{1} 1314$

The failures have been due to primary failure, late failure, aberrant and metaplastic eyelashes, and ongoing conjunctival cicatrisation. For cicatricial entropion, primary failures can be due either to inadequate shortening of the retractors or an inability of the retractor to prevent entropion because of gross posterior lamellar shortening. In this series, subsequent examination showed that these lids could easily be everted and therefore they are technical failures due to inadequate amounts of plication. Three cases were ultimately unsuccessful because there were aberrant or metaplastic eyelashes. This was despite anatomical success; such cases are not suitable for retractor plication and the lashes need permanent ablating. However, this may not be easily determined preoperatively and such lashes may be the minority of those that touch the globe when the entropion is present.
If the surgery was successful at 9 months, then recurrence was unlikely unless there was further cicatrisation. However, to achieve this, $70 \%$ of patients required systemic immunosuppression to control the preoperative inflammation. The outcome of the technique may be further improved if adequate amounts of plication are ensured at the time of surgery.

The other alternative to entropion surgery is lash ablation. Cryotherapy is successful in $40 \%$ at 1 year ${ }^{14}$ and this compares with retractor plication surgery which is successful in $54-77 \%$ at 1 year. Cryotherapy is relatively safe in OCP provided that the patients are free of inflammation at the time of surgery but not otherwise. ${ }^{14}$ Wood and Anderson ${ }^{15}$ reported marked progression of symblepharon and conjunctival scarring after cryotherapy in $77 \%$ of patients with OCP in the absence of immunosuppression. Unfortunately, cryotherapy may permanently ablate the meibomian glands and this is not beneficial in OCP. ${ }^{16}$ This complication is not a feature of retractor plication surgery. The other therapeutic alternatives for small numbers of trichiatic lashes are electrolysis ${ }^{17-20}$ and laser thermoablation ${ }^{15} 1621-25$ which have success rates of $29 \%$ and $50 \%$ respectively at 1 year in non-cicatrising disease.

Overall, for patients with cicatricial lower lid entropion and lash-globe touch not due solely to aberrant or metaplastic lashes, retractor plication surgery has the potential for the best long term outcome. Ideally, the patients should have any conjunctival inflammation resolved or minimised before surgery and adequate amounts of plication must be performed.

1 Foster CS. Cicatricial pemphigoid. Trans Am Ophthalmol Soc 1986; 84: 527-663.

2 Ormerod LD, Fong LP, Foster CS. Corneal infection in mucosal scarring disorders and Sjogren's syndrome. $A m \mathcal{F}$ Ophthalmol 1988; 105: 512-8.

3 Jones LT, Reeh MJ, Wobig JL. Senile entropion. $A m \mathcal{F}$ Ophthalmol 1972; 74: 327-9.

4 Rycroft B. The surgery of ocular pemphigus. Proc $R$ Soc Med 1961; 54: 111-2.

5 Shore JW, Foster CS, Westfall CT, Rubin PA. Results of buccal mucosal grafting for patients with medically controlled ocular cicatricial pemphigoid. Ophthalmology 1992; 99: 383-95.

6 Beyer CK. The management of special problems associated with Stevens-Johnson syndrome and ocular pemphigoid. Trans Am Acad Ophthalmol Otolaryngol 1977; 83: 701-7.

7 Mondino BJ, Brown SI, Lempert S, Jenkins MS. The acute manifestations of ocular cicatricial pemphigoid: diagnosis and treatment. Ophthalmology 1979; 86: 543-52.

8 Mondino BJ, Brown SI. Ocular cicatricial pemphigoid. Ophthalmology 1981; 88: 95-100.

9 Rosser PM, Collin JRO. Retractor plication for lower lid entropion in ocular cicatricial pemphigoid. Aust NZ Ophthalmol 1993; 21: 93-7.

10 Jones LT. The anatomy of the lower eyelid. Am $f$ Ophthalmol 1960; 49: 29-36.

11 Schwab IR, Linberg JV, Gioia VM, Benson WH, Chao GM. Foreshortening of the inferior conjunctival fornix associated with chronic glaucoma medications. Ophthalmology 1992; 99: 197-202.

12 Kahn HA, Sempos CT. Statistical methods in epidemiology. Monographs in epidemiology and biostatistics. Vol 12. Oxford: Oxford University Press, 1989: 168-98.

13 Francis IC, McCluskey PJ, Walls RS, Wakefield D, Brewer JM. Ocular cicatricial pemphigoid. Aust NZ $\mathcal{O}$ Ophthalmol 1990; 18: 143-50.

14 Elder MJ, Bernauer W. Cryotherapy for ocular cicatricial pemphigoid. Brf Ophthalmol 1994; 78: 769-71.

15 Wood JR, Anderson RL. Complications of cryosurgery. Arch Ophthalmol 1981; 99: 460-3.

16 Bartley GB, Bullock JD, Olsen TG, Lutz PD. An experimental study to compare methods of eyelash ablation. Ophthalmology 1987; 94: 1286-9.

17 Hartzler J, Nelder KH, Forster L. X-ray epilation for the treatment of trichiasis. Arch Dermatol 1984; 120: 620-4.

18 Hecht SD. Cryotherapy of trichiasis with the use of the retinal cryoprobe. Ann Ophthalmol 1977; 9: 1501-3.

19 Sullivan JH, Beard C, Bullock TD. Cryosurgery for treatment of trichiasis. Am $f$ Ophthalmol 1976; 82: 117-21. 
20 Reacher MH, Munoz B, Alghassany A, Daar AS, Elbualy M, Taylor HR. A controlled trial of surgery for trachomaM, Taylor HR. A controlled trial of surgery for trachomatous trichiasis

21 Awan KJ. Laser photocoagulation - vaporization therapy of trichiasis. Ophthalmic Laser Therapy 1988; 3: 3-9.

22 Awan KJ. Argon laser treatment of trichiasis. Ophthalmic Surg 1986; 17: 658-60.
23 Berry J. Recurrent trichiasis: treatment with laser photocoagulation. Ophthalmic Surg 1979; 10: 36-8.

24 Campbell DC. Thermoablation for trichiasis using the argon laser. Aust NZ ₹ Ophthalmol 1990; 18: 427-30.

25 Sharif KW, Arafat AF, Wykes WC. The treatment of recurrent trichiasis with the argon laser photocoagulation. Eye 1991; 5: 591-5.

History of ophthalmology

\section{Dawbeney Turberville - a seventeenth century ophthalmologist}

Next year will see the tercentenary of the death of Dawbeney Turberville, one of the earliest documented English ophthalmologists. The epitaph on his tomb in Salisbury Cathedral states ' $\mathrm{He}$ so much excelled as an oculist that he alone was known and celebrated in every part of the world, whose fame, more lasting than marble, will never perish'. Born at Wayford in Somerset in 1612, he entered Oriel College, Oxford in 1631 and was admitted bachelor of arts in 1634. After service on the Royalist side in the English Civil War he entered ophthalmic practice, initially in his home town but moved to London around 1655. He left the capital around 1660 because the air pollution affected his health. For over 30 years he practised at 17 the Cathedral Close and the house and rooms have changed little since his occupancy. His practice in London and Salisbury became well known and in 1660 Turberville received an Oxford 'doctorate in physicke', on the strength of his reputation, at the personal request of the Chancellor of the University, the Marquis of Hertford. He was not required to submit a thesis or to give a lecture series.

On visits to London, Turberville treated the daughter of the Duke of York (later Queen Anne) and Samuel Pepys, the famous naval administrator and diarist. Pepys's diary records his treatments with various eye medicaments, pills, blood letting, and tube spectacles. He also describes a meeting at an alehouse in the Strand in July 1668 where four doctors, including Turberville, dissected eyes from sheep and oxen. After this meeting he recorded his surprise 'that this Turberville should be so great a man, and yet to this day has seen no eyes dissected, or but once'. One of Turberville's most grateful patients was Walter Pope, professor of astronomy at Gresham College, London between 1660 and 1687. He received treatment in 1686 and wrote 'Turberville ... him, to whom, under God, I owe my Sight, a blessing, in my opinion, equal, if not preferable, to Life it self, without it. It was he who twice rescued me from Blindness'.

The 1685 Philosophical Transactions of the Royal Society contain three letters from 'the great and experienced Dr Turbervile of Salisbury ... containing several remarkable cases in Physick, relating chiefly to the Eyes'. Several unpublished handwritten letters are also held in the Royal Society library. The case reports include a man in Salisbury "who had a piece of Iron or Steel, stuck in the Iris of the Eye; the Person was in very great pain, came to me; I endeavr'd to push the Iron out with a small Spatula, but could not; I then applied a Loadstone to it, and immediately it jumpt out'. Pope suggested that Turberville's skill was in 'knowing when the connate Cataract is fit to be Couchd, in having a steady Hand, and skill to perform that Operation, to be able to prevent or at least, remove the pains which usually follow, and sometimes kill the Patient: But to reduce fallen and inverted Eye-lids to their proper place and Tone, to cure inveterate Ulcers, and Inflammations of a blackish colour, requires a consummate Artist. Hic Labor, hoc opus est'.

Turberville attracted patients from all over Great Britain, France, and America. One unfortunate lady came from Jamaica and was treated successfully in Salisbury, only to die of smallpox in London. The numerous patients coming to Salisbury benefited the inns and private houses and were a common sight, with bandaged eyes - 'Hoodwinkt People' - making their way to the Close. Many were recognisable, as treatment regimes included the shaving of the head and taking tobacco. Turberville continued to practise well into old age. He died on 21 April 1696 at the age of 84 years. While some later writers consider him a charlatan I concur with the view of the American medical historian Charles Snyder that, by the standards of his time, he was a competent ophthalmologist, an honourable man, adequately trained, and occasionally imaginative.

HUGH F THOMAS Salisbury, Wilts 